\title{
Contrasting Inflammatory Signatures in Peripheral Blood and Bronchoalveolar Cells Reveal Compartment-Specific Effects of HIV Infection
}

OPEN ACCESS

Edited by:

Donata Medaglini,

University of Siena, Italy

Reviewed by:

Roger Le Grand,

Commissariat à l'Energie Atomique et aux Energies Alternatives

(CEA), France

Helder Nakaya

University of São Paulo, Brazi

*Correspondence:

Emily B. Wong

emily.wong@ahri.org

tThese authors have contributed equally to this work

Specialty section: This article was submitted to Mucosal Immunity, a section of the journal

Frontiers in Immunology

Received: 28 October 2019 Accepted: 15 April 2020

Published: 19 May 2020

Citation:

Muema DM, Mthembu M, Schiff AE, Singh U, Corleis B, Chen D, Bassett T,

Rasehlo SS, Nyamande K, Khan DF, Maharaj P, Mitha M, Suleman M. Mhlane Z, Naidoo T, Ramjit D, Karim F, Kwon DS, Ndung'u T and Wong EB (2020) Contrasting Inflammatory Signatures in Peripheral Blood and Bronchoalveolar Cells Reveal Compartment-Specific Effects of HIV Infection. Front. Immunol. 11:864 doi: 10.3389/fimmu.2020.00864
Daniel M. Muema ${ }^{1,2,3+}$, Maphe Mthembu ${ }^{1 \dagger}$, Abigail E. Schiff ${ }^{4,5}$, Urisha Singh ${ }^{1}$, Björn Corleis ${ }^{4,6}$, Dongquan Chen ${ }^{7}$, Thierry Bassett ${ }^{1}$, Sipho S. Rasehlo ${ }^{1}$, Kennedy Nyamande ${ }^{8}$, Dilshaad Fakey Khan ${ }^{8}$, Priya Maharaj ${ }^{8}$, Mohammed Mitha ${ }^{8}$, Moosa Suleman ${ }^{8}$, Zoey Mhlane ${ }^{1}$, Taryn Naidoo ${ }^{1}$, Dirhona Ramjit ${ }^{1}$, Farina Karim ${ }^{1}$, Douglas S. Kwon ${ }^{4,5,9}$, Thumbi Ndung'u 1,2,4,10,11 and Emily B. Wong 1,5,9,10*

${ }^{1}$ African Health Research Institute, Durban, South Africa, ${ }^{2}$ HIV Pathogenesis Programme, The Doris Duke Medical Research Institute, University of KwaZulu-Natal, Durban, South Africa, ${ }^{3} \mathrm{KEMRI-Wellcome} \mathrm{Trust} \mathrm{Research} \mathrm{Programme,} \mathrm{Kilifi,} \mathrm{Kenya,}$ ${ }^{4}$ Ragon Institute of MGH, MIT and Harvard, Cambridge, MA, United States, ${ }^{5}$ Department of Medicine, Harvard Medical School, Boston, MA, United States, ${ }^{6}$ Institute of Immunology, Friedrich-Loeffler-Institute, Federal Research Institute for Animal Health, Greifswald, Isle of Riems, Germany, ${ }^{7}$ Department of Medicine, The University of Alabama at Birmingham, Birmingham, AL, United States, ${ }^{8}$ Department of Pulmonology, Inkosi Albert Luthuli Central Hospital, Nelson R. Mandela School of Medicine, College of Health Sciences, University of KwaZulu-Natal, Durban, South Africa, ${ }^{9}$ Division of Infectious Diseases, Massachusetts General Hospital, Boston, MA, United States, ${ }^{10}$ Division of Infection and Immunity, University College London, London, United Kingdom, ${ }^{11}$ Max Planck Institute for Infection Biology, Berlin, Germany

The mechanisms by which HIV increases susceptibility to tuberculosis and other respiratory infections are incompletely understood. We used transcriptomics of paired whole bronchoalveolar lavage cells (BLCs) and peripheral blood mononuclear cells to compare the effect of HIV at the lung mucosal surface and in peripheral blood. The majority of HIV-induced differentially expressed genes (DEGs) were specific to either the peripheral or lung mucosa compartments (1,307/1,404, 93\%). Type I interferon signaling was the dominant signature of DEGs in HIV-positive blood but not in HIV-positive BLCs. DEGs in the HIV-positive BLCs were significantly enriched for infiltration with cytotoxic $\mathrm{CD}^{+} \mathrm{T}$ cells. Higher expression of type 1 interferon transcripts in peripheral $\mathrm{CD}^{+}{ }^{+} \mathrm{T}$ cells and representative transcripts and proteins in BLCs-derived CD8 ${ }^{+} \mathrm{T}$ cells during HIV infection, including IFNG (IFN-gamma), GZMB (Granzyme B), and PDCD1 (PD-1), was confirmed by cell-subset specific transcriptional analysis and flow cytometry. Thus, we report that a whole transcriptomic approach revealed qualitatively distinct effects of HIV in blood and bronchoalveolar compartments. Further work exploring the impact of distinct type I interferon programs and functional features of $\mathrm{CD}^{+}{ }^{+} \mathrm{T}$ cells infiltrating the lung mucosa during HIV infection may provide novel insights into HIV-induced susceptibility to respiratory pathogens.

Keywords: HIV, type I interferon, Cytotoxic CD8 T cells, lymphocyte infiltration, bronchoalveolar 


\section{INTRODUCTION}

HIV is a major cause of morbidity and mortality in sub-Saharan Africa. South Africa bears the highest burden globally with $\sim 7.7$ million people living with HIV in 2018 (1). Introduction of immediate antiretroviral therapy (ART) following diagnosis has greatly improved long-term outcomes and life expectancy in people living with HIV. However, $46 \%$ of people living with HIV in South Africa are still viremic either because they don't know their HIV status or due to treatment failure (1).

HIV-infected viremic patients are more likely to develop active tuberculosis (TB) from either new exposure to $M$. tuberculosis $(\mathrm{Mtb})$ or reactivation of a pre-existing latent $\mathrm{Mtb}$ infection when compared to HIV-uninfected and HIV-infected non-viremic individuals $(2,3)$. T helper 1 (Th1) polarized CD $4^{+}$ $\mathrm{T}$ cells that produce interferon gamma and TNF-alpha are thought to play a significant role in controlling TB infection, and their depletion in HIV-infected individuals may contribute to the increased risk of TB disease $(4,5)$. However, the risk of developing active TB increases even before significant $\mathrm{CD} 4^{+} \mathrm{T}$ cell depletion, doubling within the first year of HIV infection, suggesting that other HIV-induced modulations of the immune system could contribute to the increased risk of TB in people with HIV (6). Indeed, HIV infection has been shown to decrease the polyfunctional cytokine production in Mtb-specific $\mathrm{CD} 4^{+} \mathrm{T}$ cells independent of $\mathrm{CD} 4^{+} \mathrm{T}$ cell depletion $(7,8)$. Additionally, HIV infection is associated with reduced phagocytic potential of alveolar macrophages, an effect that could reduce the initial innate immune barrier to TB infection (9).

Strategies to enhance control of Mtb in HIV-infected and uninfected persons are hindered by our limited understanding of the natural immunological control of $\mathrm{Mtb}$ and the mechanisms underlying progression from latent Mtb infection to disease. Hypothesis-driven targeted studies may miss important pathways that could inform the understanding of TB immunopathogenesis. In contrast, high throughput approaches have the potential to offer unbiased insights into the immune defects mediated by HIV, and thus advance the field of TB immunopathogenesis. One such approach is harnessing genome wide transcriptomic data to provide mechanistic insights into the immunologic pathways that are defective in patients who are likely to get infected with $\mathrm{TB}$ or progress to active disease, such as HIV-positive patients (10-14). The use of whole blood or unsorted peripheral blood mononuclear cells (PBMCs) in transcriptomic studies has the advantage of giving an overall picture of the immune profiles that are associated with development of TB. For instance, transcriptomic analyses of whole peripheral blood in tuberculosis has pointed to the development of a type 1 interferon signature (10). Notably, even though it is established that HIV disrupts lung immunity and increases risk of TB disease, these whole genome studies have not investigated the effect of HIV in the lung, the site of Mtb exposure; most of the work has been on samples from peripheral blood because they are easily accessible.

In this study, we assessed the differences in immune profiles between blood and the bronchoalveolar compartments using whole compartment and sorted $\mathrm{CD} 8^{+} \mathrm{T}$ cells by ribonucleic acid sequencing (RNA-seq) and flow cytometry. We also assessed the compartment-specific effects of HIV to comprehensively explore and describe the immunological defects that could explain the increased lung comorbidities, especially TB disease, in HIVinfected individuals. We report that while HIV induces primarily a type I interferon signature in blood, its primary signature in the bronchoalveolar compartment is an induction of a cytotoxic $\mathrm{CD}^{+}{ }^{+} \mathrm{T}$ cell infiltrate.

\section{METHODS}

\section{Study Population}

We studied the effect of HIV on immune function in the peripheral blood and bronchoalveolar compartment using two bronchoalveolar study cohorts at African Health Research Institute (AHRI) in KwaZulu-Natal, South Africa. The first cohort was a hospital-based cohort in which we recruited HIVnegative or HIV-positive ART-naive participants ( $>18$ years) who came for clinical investigations but were determined (after extensive work-up including bronchoscopy and bronchoalveolar microbiological investigations) to not have any infectious or inflammatory pulmonary disease. Their clinical indications and final diagnosis are documented in Supplemental Table 1. Participants were consented for research use of clinically excess BAL fluid and a paired peripheral blood draw. The second cohort was a research bronchoscopy cohort of HIV-negative and HIV-positive adults (18-50 years). Exclusion criteria included: pregnancy, any history of disease other than HIV, history of ART, and smoking. Study participants were recruited from KwaDabeka Community Health Centre. All participants were confirmed to be free of respiratory symptoms and to have a normal chest X-ray. Further, HIV-positive participants were confirmed to have a negative sputum Mtb GeneXpert. The HIV status of all participants was determined by fourth generation HIV antibody/antigen Enzyme Linked-Immunosorbent Assay (ELISA) testing and HIV RNA quantitative viral load. $\mathrm{CD} 4^{+} \mathrm{T}$ cell counts were determined in all participants. All participants also underwent assessment of hemoglobin (had at least $10 \mathrm{~g} / \mathrm{dL}$ ), platelet level (had at least $100 \times 10^{9}$ cell/L) and prothrombin time [international normalized ratio (INR) $<1.3$ ] to meet safety criteria for bronchoscopy. Once screened and characterized, participants were transported to Inkosi Albert Luthuli Central Hospital (IALCH) where they underwent research bronchoscopy and paired peripheral blood draw. All participants provided written informed consent. Both study protocols were approved by the University of KwaZulu-Natal Biomedical Research Ethics Committee (BREC; reference numbers BF503/15 and BE037/12) and Partners Institutional Review Board.

Participant samples were selectively subjected (depending on sample availability for different techniques) to differential cell count, mitogen stimulation, monoclonal antibody staining, and transcriptomic analysis.

\section{Sample Processing and Differential Cell Counts}

Bronchoscopies were performed by pulmonologists at IALCH with participants receiving sedation and bronchodilators 
according to local standard of care protocols. Two hundred milliliters of normal saline were infused into the right middle lobe. Bronchoalveolar lavage fluid was stored at $4{ }^{\circ} \mathrm{C}$ and processed in the laboratory within $90 \mathrm{~min}$. Paired peripheral blood was collected in acid citrate dextrose (ACD) tubes (BD, Franklin Lakes, NJ, USA) and stored at room temperature. A portion of the sample was directly used for differential cell counts in each compartment after standard preparation and interpretation of peripheral blood smear and cytospin slide for BAL fluid. PBMCs were isolated using standard Histopaque (Sigma-Aldrich, St. Louis, MO, USA) gradient centrifugation protocols.

To isolate bronchoalveolar lavage fluid cells (BLCs), BAL fluid was passed through a $40 \mu \mathrm{m}$ filter (BD). The fluid was spun at $524 \mathrm{~g}$ for $10 \mathrm{~min}$ at $4^{\circ} \mathrm{C}$ and all cells resuspended in RPMI media supplemented with 5\% fetal bovine serum, $1 \%$ penicillin/streptavidin, 1\% HEPES buffer, and 1\% amphotericin. The cells were freshly used for monoclonal antibody staining and mitogen stimulation to test functionality.

\section{Flow Cytometry}

The BLCs and PBMCs were counted and assessed for viability using trypan blue (Sigma-Aldrich) and compound microscopy to ensure $>90 \%$ lymphocyte viability. To assess distribution of $\mathrm{CD}^{+}$and $\mathrm{CD}^{+} \mathrm{T}$ cells, immune regulation and functionality of $\mathrm{CD}^{+} \mathrm{T}$ cells in HIV infection, cells from the two compartments were subjected to two panels of fluorescently labeled antibodies. Panel 1 (phenotypic panel): Live/dead-amcyan (Life Technologies, Carlsbad, CA, USA), CD3-BV650, CD4-BV711, CD14-APC-Cy7, PD-1-BV711, TIM3-BV785 (BioLegend, San Diego, CA, USA), and CD8PE Texas Red (Invitrogen, Carlsbad, CA, USA). Panel 2 (intracellular cytokine staining panel): Live/dead-amcyan (Life Technologies), CD3-Alexa700, CD4-BV711, CD8-APC-Cy7, granzyme b-Alexa647, IFN $\gamma$-Dazzle 549 (BioLegend). Panel 2 staining was done after stimulation with PMA/Ionomycin $(25 / 500 \mathrm{ng} / \mathrm{mL})$. Acquisition was performed on BD FACS Aria III. Flowjo v10.5 (Flowjo, LLC) was used for flow cytometry analysis.

\section{RNA Isolation From Whole BAL}

Freshly processed cellular pellets from bronchoalveolar lavage (1 mL of BAL fluid) and Histopaque gradient-isolated PBMCs $\left(1 \times 10^{6}\right.$ cells $)$ from the hospital cohort for bulk sequencing were stored in RNAlater stabilizing reagent (Sigma-Aldrich) at $-80^{\circ} \mathrm{C}$. Samples were later thawed at room temperature, pelleted, and suspended with $1 \% \beta$-mercaptoethanol RLT buffer from the Qiagen RNeasy Micro kit (Qiagen, Hilden, Germany). Extraction of RNA was performed according to manufacturer's protocol. Briefly, a QIAshredder column was used to homogenize the samples. DNAse 1 treatment was used to eliminate any remaining genomic DNA contamination. The extracted RNA was quantified using nanodrop and aliquoted into $\sim 200 \mathrm{ng}$ aliquots, adequate for RNASeq library preparation. All aliquots were immediately stored at $-80^{\circ} \mathrm{C}$.

\section{Sorted CD8 ${ }^{+}$T Cell Populations}

For work on purified $\mathrm{CD}^{+} \mathrm{T}$ cells, freshly processed cells from the hospital cohort were sorted into 70\% TRIzol LS Reagent (Thermo Fisher Scientific, Waltham, MA, USA) and stored at $-80^{\circ} \mathrm{C}$. Both RNA and DNA were isolated from these samples using the TRIzol/chloroform method with minor modifications. Briefly, RNA was precipitated using a nucleic acid co-precipitant, $5 \mathrm{mg} / \mathrm{mL}$ linear acrylamide (Thermo Fisher Scientific). All reagents were kept at $4^{\circ} \mathrm{C}$ to facilitate separation of nucleic acid into different layers and efficient precipitation. QIAGEN RNeasy Micro kit was used to purify RNA from the TRIzol extracted samples. The quality of the extracted RNA was determined using the BioAnalyzer RNA Pico kit (Agilent, Santa Clara, CA, USA).

\section{RNA-seq Library Preparation and Sequencing}

Enrichment for messenger RNA was done using the NEBNext Poly(A) mRNA Magnetic Isolation kit (New England Biolabs, Ipswich, MA, USA). RNA libraries were prepared using the NEBNext Ultra RNA Library Prep Kit for Illumina (New England Biolabs). Dual index primers from the NEBNext Multiplex Oligos for Illumina kit were used to label the samples. A subset of the libraries was assessed for acceptable quality using the BioAnalyzer DNA High Sensitivity Chip or the DNA TapeStation (Agilent). Concentrations of the libraries were determined using a Qubit dsDNA assay kit (Thermo Fisher). Equal molarities of the indexed libraries were pooled and sequenced on an Illumina NextSeq 500 platform to yield $75 \mathrm{bp}$ paired end reads. The RNA-seq libraries for all the bulk samples were prepared and sequenced in a single batch to avoid batch effects. Likewise, the RNA-seq libraries for the sorted CD8 $\mathrm{T}$ cells were generated and sequenced in a single batch.

\section{Sequencing Data Analyses}

The raw data were demultiplexed and processed using Trimmomatic version 0.36 to remove adaptors and leading/trailing low-quality bases. Subsequent analyses were done using the Tuxedo protocol as previously described (15). Briefly, the sequences were aligned on the human reference genome GRCh37 (hg19) using the TopHat module (version 2.1.1) and Bowtie (version 2.2.4). The mapped reads were then sorted using the Picard SortSam module. Duplicate reads were identified using the Picard MarkDuplicates module and removed. The Cufflinks module (Version 2.2.1) was used for subsequent analyses. The transcripts for each sample were assembled and the numbers of reads quantified for each transcript. The expression levels were expressed as Fragments Per Kilobase of transcript per Million fragments mapped (FPKM). The assembled transcripts for all samples were merged to obtain a master transcriptome assembly (Cuffmerge) followed by assessment of differential expression (Cuffdiff). A statistically significant difference in the expression of a transcript between two groups of participants was defined as having at least a two-fold difference and $q<0.05$ (after Benjamini-Hochberg correction for multiple-testing). CummeRbund $\mathrm{R}$ package 
TABLE 1 | Demographic and clinical characteristics of the study population.

\begin{tabular}{lccc}
\hline Characteristics & HIV-Negative & HIV-Positive & $P$-value \\
\hline$N$ & 19 & 11 & NA \\
Sex, No. of females (\%) & $9(47)$ & $6(54)$ & $>0.9999$ \\
Age in years, median & $36(32-44)$ & $31(30-40)$ & 0.3883 \\
(IQR) & & & \\
CD4 counts in cells/ $\mu$ L, & 1,048 & $353(173-576)$ & $<0.0001$ \\
median (IQR) & $(854-1,352)$ & & \\
$\begin{array}{l}\text { Viral load in copies/mL, } \\
\text { median (IQR) }\end{array}$ & 0 & 54,942 & NA \\
\hline
\end{tabular}

Data presented in median and interquartile range unless stated otherwise. MannWhitney U-test was used to calculate significance between the two study groups. In the comparison for gender distribution between the groups, Chi-square test was used. IQR, interquartile range; $N A$, not applicable.

(version 2.16), GraphPad Prism (version 8), and MorpheusBroad Institute (https://software.broadinstitute.org/morpheus/) were used for subsequent data visualization. Identification of HIV-induced pathway changes was done on the GOrilla platform (http://cbl-gorilla.cs.technion.ac.il/) by checking for enriched Gene Ontology (GO) terms among the differentially expressed genes (16). To exclude very large or very small nonspecific GO terms that did not have specific biological implications, an arbitrary cut-off was set whereby only GO terms whose sizes are between 20 and 200 genes were considered in the analyses. The LM22 leukocyte gene signature matrix was used in the CIBERSORT platform for deconvolution analyses to estimate the proportions of 22 leukocytes populations in the RNA-seq samples (17).

\section{Statistical Analyses}

Comparisons of flow cytometry data and differential counts data between HIV-uninfected and HIV-infected groups were assessed using the Wilcoxon rank-sum test. Matched comparisons of flow cytometry data and differential counts data between blood and bronchoalveolar lavage samples were assessed using the Wilcoxon matched pairs signed rank test. Differences were considered statistically significant if $p<0.05$. Comparisons of ratios of participants between groups were done using Chi-square test. All statistical analyses were done on GraphPad Prism version 8 (GraphPad Software, Inc).

\section{RESULTS}

\section{Population Characteristics}

We used matched blood and bronchoalveolar fluid samples that were collected from $19 \mathrm{HIV}$-negative participants (15 from the research bronchoscopy cohort and 4 from the hospitalbased cohort) and 11 HIV-positive participants ( 8 from the research bronchoscopy cohort and 3 from the hospital-based cohort; Table 1). The median age of all participants was 34 years and $50 \%$ of the participants were female. There were no significant differences in age or sex distribution between the HIV-negative and HIV-positive groups. All HIVinfected participants were ART-naïve. The median viral load for the HIV-infected group was 54,942 copies/mL [Interquartile range (IQR): 18,743-174,293]. The median $\mathrm{CD}^{+}$T-cell counts for the HIV-uninfected and HIV-infected groups were 1,048 cells $/ \mathrm{mm}^{3}$ (IQR: 854-1,352) and 353 (IQR: 173-576), respectively $(p<0.0001)$.

\section{Distribution of Major Immune Cell Populations in Bronchoalveolar Compartment and Blood}

To determine the HIV-specific effects on the distribution of major populations of immune cells within each anatomical compartment, we used matched samples from the bronchoalveolar compartment and blood to conduct two-way comparisons, i.e., between disease states within each compartment (horizontal comparisons, Figure 1A) and between compartments (vertical comparisons). We carried out differential cell counts to enumerate differences in distribution of key immune cell populations between the two compartments (Figure 1B). In both HIV-negative and HIV-positive individuals, distributions of immune cells were significantly different between the two compartments (Figure 1C). In both groups, alveolar macrophages were the dominant immune cells in the bronchoalveolar compartment with medians of $87.4 \%$ [interquartile range (IQR): 79.8-90] and 79.3 [interquartile range (IQR): 70.9-88] among HIV-negative and HIV-positive persons, respectively (Figure $\mathbf{1 C}$ and Supplementary Table 2). On the other hand, lymphocytes and neutrophils were the dominant immune cells in the peripheral blood in both groups. Notably, the distributions of major immune cells within compartments were not significantly different between HIV-negative and HIV-positive participants.

We then used flow cytometry to further assess if there were HIV-specific alterations within the lymphocyte populations. The proportions of total $\mathrm{T}$ cells $\left(\mathrm{CD}^{+}\right.$cells) were reduced in the PBMCs but increased in BLCs of HIV-positive patients, consistent with $\mathrm{HIV}$-associated T-cell infiltration in bronchoalveolar compartment $(p=0.0030$ and 0.0473 , respectively, Figure 1D). The reduction of proportions of $\mathrm{CD}^{+}$ lymphocytes in PBMCs of HIV-positive study participants was primarily due to the loss of $\mathrm{CD} 4^{+} \mathrm{T}$ cells as shown by the reduction in proportions of $\mathrm{CD}^{+} \mathrm{T}$ cells in PBMCs $(p=$ $0.0001)$. We observed similar reduction in proportions of $\mathrm{CD}^{+}$ $\mathrm{T}$ cells in the BLCs of HIV-positive participants $(p<0.0001$; Figure 1E). Notably, we observed an HIV-associated increase in proportions of $\mathrm{CD}^{+} \mathrm{T}$ cells in both PBMCs $(p=0.002)$ and BLCs $(p<0.0001)$ (Figure 1F). In further, separate analyses of the research bronchoscopy cohort and the hospital-based cohort, we observed a similar HIV-associated increase in proportions of $\mathrm{CD} 8^{+} \mathrm{T}$ cells and a reduction in proportions of $\mathrm{CD}^{+} \mathrm{T}$ cells in the BLCs and PBMCs (Supplementary Figures 1A,B,D,E). Thus, HIV was associated with an increase in proportions of $\mathrm{CD}^{+} \mathrm{T}$ cells and a decrease in proportions of $\mathrm{CD} 4^{+} \mathrm{T}$ cells in both blood and bronchoalveolar compartments in multiple cohorts. These findings are in agreement with previous studies that have reported increased proportions of $\mathrm{CD} 8^{+} \mathrm{T}$ cells and decreased proportions of CD4 ${ }^{+} \mathrm{T}$ cells in the bronchoalveolar compartment of HIV-positive individuals $(8,18,19)$. 
A

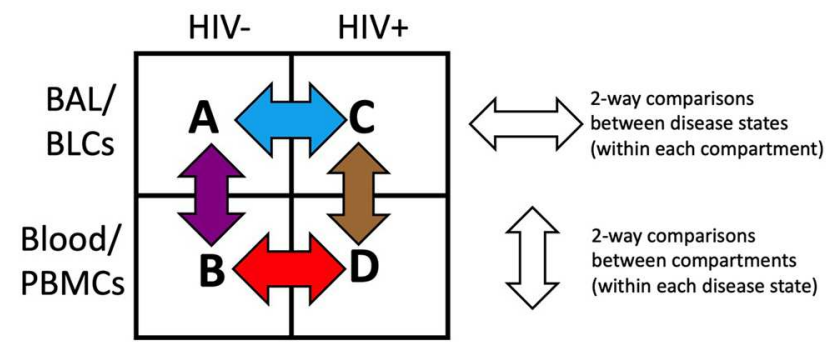

B

Blood cells differential counts

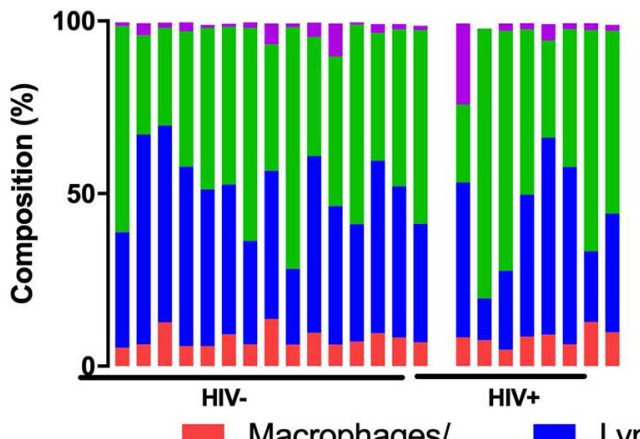

Macrophages/ Monocytes
BAL cells differential counts

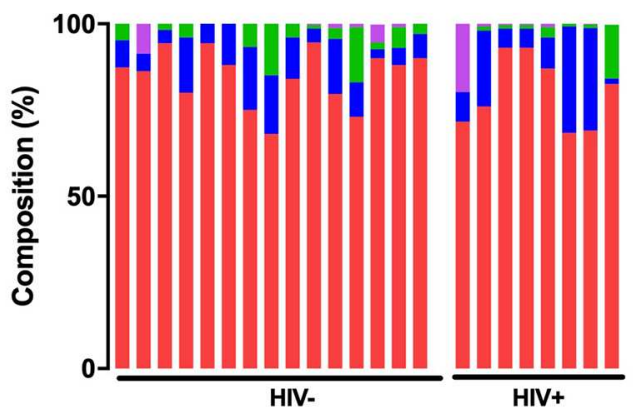

Neutrophils

Eosinophils

C

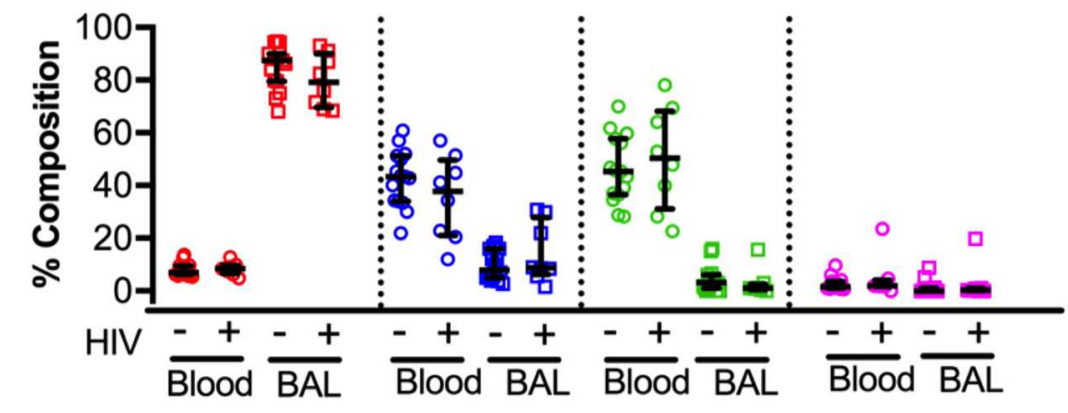

Macrophages/ Lymphocytes $\square$ Neutrophils $\square$ Eosinophils
Monocytes

D

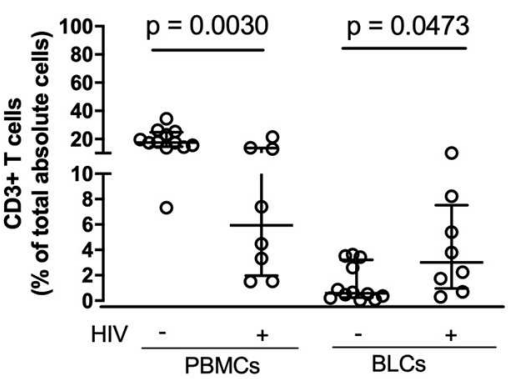

E

CD4 T cells

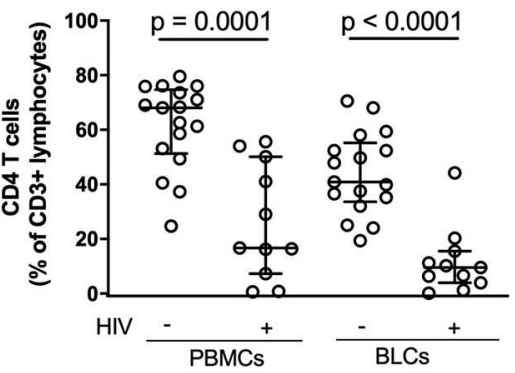

CD8 T cells

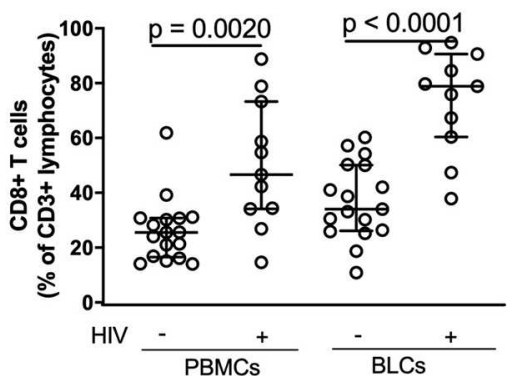

FIGURE 1 | Comparisons of the immune cell sub-types between peripheral blood and bronchoalveolar lavage (BAL) cells of both HIV-negative and HIV-positive individuals. (A) Two-way comparison of the study groups to understand inter-compartment differences and the impact of HIV on immune function. (B) Proportion of 
FIGURE 1 | immune cell subsets in the paired peripheral blood and bronchoalveolar cells in the HIV-negative $(n=15)$ and HIV-positive groups $(n=8)$. (C) Quantitative comparison of panel (B), showing level of significance between compartments in both HIV-negative and HIV-positive groups. (D) Proportions of total absolute CD3 ${ }^{+} \mathrm{T}$ cells in BLCs and PBMCs in HIV-positive $(n=8)$ and HIV-negative groups $(n=15)$. (E) Percentage CD4 ${ }^{+} \mathrm{T}$ cells of CD3 ${ }^{+} \mathrm{T}$ cells in BLCs and PBMCs in HIV-positive $(n=11)$ and HIV-negative groups $(n=19)$. (F) Percentage of CD8 ${ }^{+}$T cells in BLCs and PBMCs in HIV-positive $(n=11)$ and HIV-negative groups $(n=19)$.

A

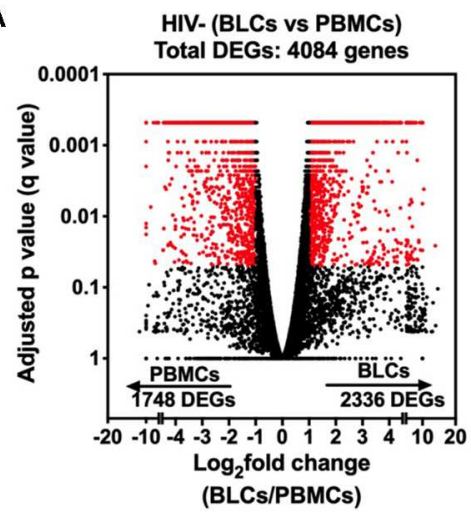

D

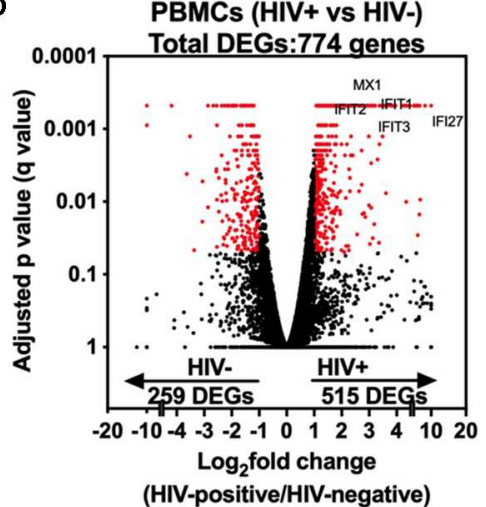

B

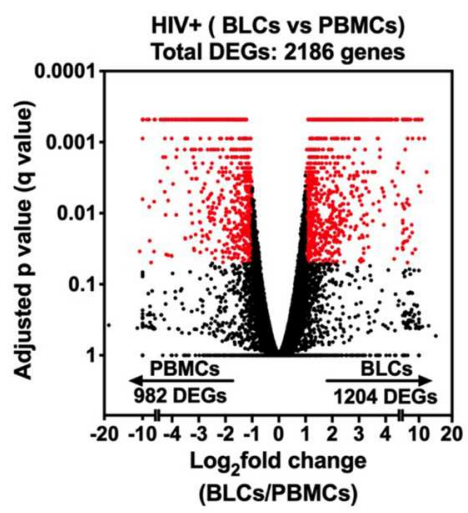

E

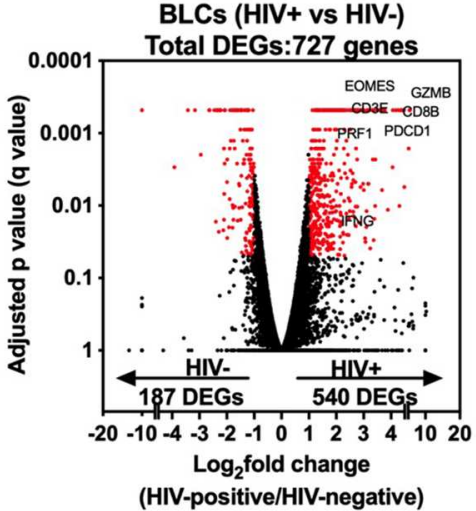

C

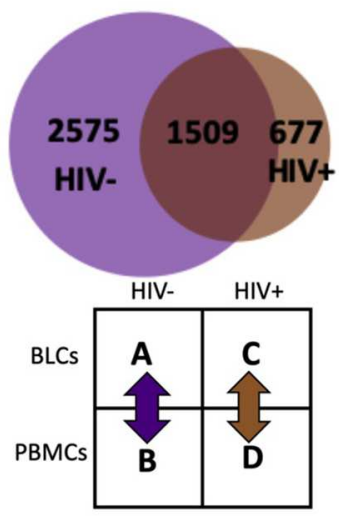

$\mathbf{F}$
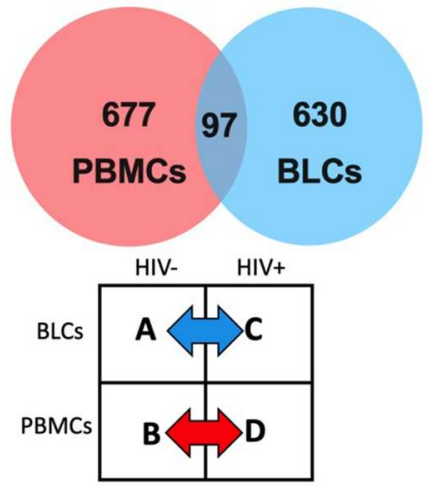

FIGURE 2 | Comparisons in transcriptomic profiles between bronchoalveolar lavage fluid cells (BLCs) and peripheral blood mononuclear cells (PBMCs) in HIV-infected and HIV-uninfected participants. (A) Differentially expressed genes between BLCs and PBMCs in the HIV-negative group $(n=4)$. (B) Differentially expressed genes between BLCs and PBMCs in the HIV-positive group $(n=3)$. (C) Numbers of differentially expressed genes between BLCs and PBMCs in both HIV-positive $(n=3)$ and HIV-negative groups $(n=4)$. (D) Differentially expressed genes between HIV-negative $(n=4)$ and HIV-positive $(n=3)$ groups in PBMCs. (E) Differentially expressed genes between HIV-negative and HIV-positive groups in BLCs. (F) Numbers of differentially expressed genes between HIV-negative and HIV-positive groups in both PBMCs and BLCs.

\section{HIV Infection Is Associated With Compartment-Specific Changes in the Transcriptional Profile in BLCs and PBMCs}

To first assess transcriptome-wide differences between compartments, we used RNA-seq to determine RNA expression differences between BLCs and PBMCs in four HIV-uninfected participants and three HIV-infected participants from the hospital-based cohort. Except for one PBMCs sample, we obtained at least 1 million unique forward and reverse reads for each sample after deduplication.
There were 4,761 differentially expressed genes (DEGs) between the BLCs and PBMCs in either HIV-positive or HIVnegative participants. Of these, there were 4,084 DEGs between BLCs and PBMCs in the HIV-negative group, with 2,336 genes having increased abundance and 1,748 genes having decreased abundance in BLCs when compared with PBMCs (Figure 2A). On the other hand, there were 2,186 DEGs between BLCs and PBMCs in the HIV-positive group, with 1,204 genes having increased abundance and 982 genes having decreased abundance in BLCs when compared with PBMCs (Figure 2B). Notably, the large majority of the DEGs [69\% (1,509 out of 2,186)] 
between compartments in the HIV-positive individuals were also differentially expressed between compartments in the HIVnegative individuals (Figure 2C).

To assess the compartment-specific effects of HIV, we then checked for differences between the HIV-negative and HIVpositive groups within each compartment. There were 774 DEGs in PBMCs between the HIV-positive and the HIV-negative groups, with 515 genes having increased abundance and 259 genes having decreased abundance in the HIV-positive group (Figure 2D). On the other hand, there were 727 DEGs in BLCs in comparisons between the HIV-positive group and the HIVnegative group, with 540 genes having increased abundance and 187 genes having decreased abundance in the HIV-positive group (Figure 2E). Notably, of the DEGs in either the BLCs or the PBMCs between disease states, only a very small minority $(6.9 \%, 97$ of 1,404$)$ were differentially expressed in both compartments. Thus, HIV-induced transcriptional alterations were compartment-specific (Figure 2F).

Using gene ontology (GO) analyses to annotate enriched functions in the compartment specific HIV-induced transcriptional changes, we identified $34 \mathrm{GO}$ terms that were significantly enriched (FDR $q<0.05$ ) in our list of DEGs in PBMCs between the HIV-positive and HIV-negative groups (Supplementary Table 3). We also identified 131 significantly enriched GO terms in BLCs between the HIV-positive and HIVnegative groups (Supplementary Table 4). The top enriched GO term in the PBMCs of HIV-positive participants was the "type I interferon signaling pathway" gene set (Figure 3A). On the other hand, the most enriched GO term in the BLCs of HIV-positive participants was the "adaptive immune response" gene set (Figure 3B). We also observed some enrichment of the "response to interferon-beta" and "type I interferon signaling pathway" GO terms in the BLCs of HIV-positive participants, but those GO terms ranked low in our list (Supplementary Table 4). Thus, even though HIV also induces a type I interferon signaling signature in bronchoalveolar compartment, its dominant effect there is the modulation of adaptive immune responses.

Enrichment of the "type I interferon signaling pathway" gene set in HIV-positive PBMCs was due to increased abundance of 20 genes, namely EGR1, IFI27, IFI35, IFI6, IFIT1, IFIT2, IFIT3, IFITM3, IRF4, IRF7, ISG15, MX1, MX2, OAS1, OAS2, OAS3, OASL, STAT1, XAF1, and RSAD2. On the other hand, enrichments of the "type I interferon signaling pathway" and the "response to interferon-beta" gene sets in HIV-positive BLCs were due to increased abundance of 14 genes, namely EGR1, IFITM1, IFITM2, IFITM3, IRF1, IRF3, IRF4, IRF7, ISG15, ISG20, RSAD2, AIM2, CDC34, and PYHIN1 (Figure 3C). Notably, from the above lists of 28 type I interferon-associated genes that were differentially expressed in either of the two compartments, only six (namely EGR1, IFITM3, IRF4, IRF7, ISG15, and RSAD2) were differentially expressed in both compartments, suggesting differences between the compartments.

In BLCs, enrichment of the "adaptive immune response" gene set was attributable to the HIV-induced increase in abundance for transcripts that suggested infiltration with cytolytic $\mathrm{T}$ cells, such as the lineage transcripts for $\mathrm{CD} 8^{+} \mathrm{T}$ cells $(C D 3 D, C D 3 E, C D 3 G$, $C D 8 A$, and $C D 8 B$ ), $C D 8^{+}$T-cell effector molecules [granzyme $\mathrm{M}$
(GZMM), perforin (PRF1) and interferon gamma (IFNG)] and the $\mathrm{CD} 8^{+}$T-cell transcription factors (e.g., EOMES; Figure 3C). We also observed contribution by inhibitory/exhaustion markers [PD-1 (PDCD1) and LAG-3 (LAG3)] in the enrichment of this GO term. Further observation of B-cell transcripts (CD19, $C D 79 A$, and $C D 79 B$ ) suggests that HIV also induces infiltration of the bronchoalveolar compartment by other lymphocytes as previously reported (18) (Figure 3C).

Since the GO analyses suggested lymphocyte infiltration into the bronchoalveolar compartment, we evaluated this possibility further using computational deconvolution (CIBERSORT) to estimate the representation of 22 leukocyte populations (based on the LM22 signature matrix) in the BLCs and PBMCs transcriptional data (17). This analysis demonstrated that the calculated proportion of $\mathrm{CD} 8^{+} \mathrm{T}$ cells were higher in the BLCs of HIV positive individuals when compared to the BLCs of HIV negative individuals (medians 29 and 6.5\%, respectively, Supplementary Figure 2).

The whole compartment transcriptomic approach limited our ability to confidently attribute the transcripts of effector molecules to any specific cell type, and in particular the infiltrating $\mathrm{CD}^{+} \mathrm{T}$ cell population which appeared the most likely candidate based on transcriptome profile and deconvolution analysis. We therefore assessed the HIVassociated and compartmental-associated transcriptional differences in $\mathrm{CD}^{+} \mathrm{T}$ cells using flow cytometry and RNAseq on sorted $\mathrm{CD} 8^{+} \mathrm{T}$ cells. This was also an opportunity to compare the transcriptional features of BLCs-derived $\mathrm{CD} 8^{+}$ $\mathrm{T}$ cells and PBMCs-derived $\mathrm{CD}^{+} \mathrm{T}$ cells to gain insight into the nature of the infiltrating $\mathrm{CD} 8^{+} \mathrm{T}$ cells in the HIV-positive group. Similar to observations in the whole compartment transcriptional analysis, the comparisons between compartments within each disease state showed larger numbers of DEGs than the comparisons between the disease states within each compartment. There were 110 DEGs between the BLC-derived $\mathrm{CD}^{+} \mathrm{T}$ cells and PBMC-derived $\mathrm{CD}^{+}{ }^{+} \mathrm{T}$ cells in the HIVnegative participants. On the other hand, there were 102 DEGs in similar intercompartment comparisons in HIV-positive participants (Supplementary Figures 3A-C). In the comparison between the HIV-positive and the HIV-negative groups within each compartment, there were 32 and 16 differentially expressed genes in PBMCs-derived and BLCs-derived CD8 T cells, respectively (Supplementary Figures 3D-F). GO analyses of the transcripts that were differentially expressed in comparisons between BLC-derived $\mathrm{CD} 8^{+} \mathrm{T}$ cells and PBMCs-derived $\mathrm{CD} 8^{+}$ $\mathrm{T}$ cells of HIV-negative individuals demonstrated enrichments in GO terms associated with antigen presentation in the BLCsderived $\mathrm{CD}^{+} \mathrm{T}$ cells (Supplementary Figures 4A, 5A and Supplementary Table 5). In contrast, there was an enrichment of GO terms associated with cellular migration and adhesion in BLCs-derived CD8 T cells of HIV-positive individuals when compared with matched $\mathrm{PMBC}$-derived $\mathrm{CD} 8^{+} \mathrm{T}$ cells (Supplementary Figures 4B, 5B and Supplementary Table 6). Interestingly, we observed an enrichment of GO terms that contained type I interferon inducible genes, among other genes, in PBMCs-derived $\mathrm{CD}^{+} \mathrm{T}$ cells of HIV-positive individuals when compared to HIV-negative individuals. 
A

\section{PBMCs}

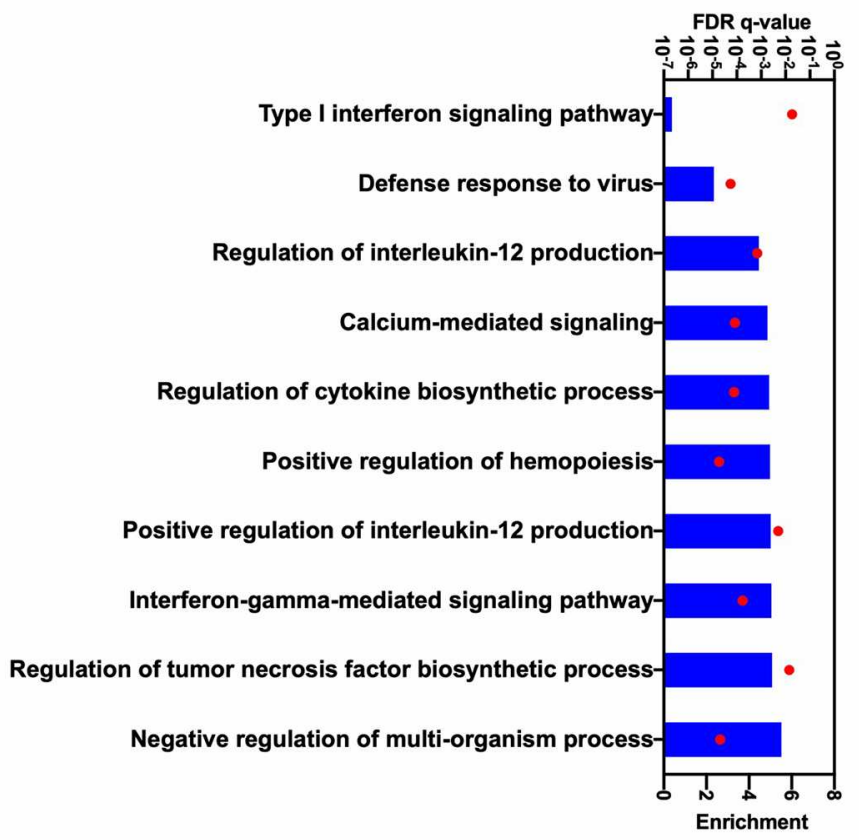

- Enrichment

FDR q-value

B

\section{BLCs}

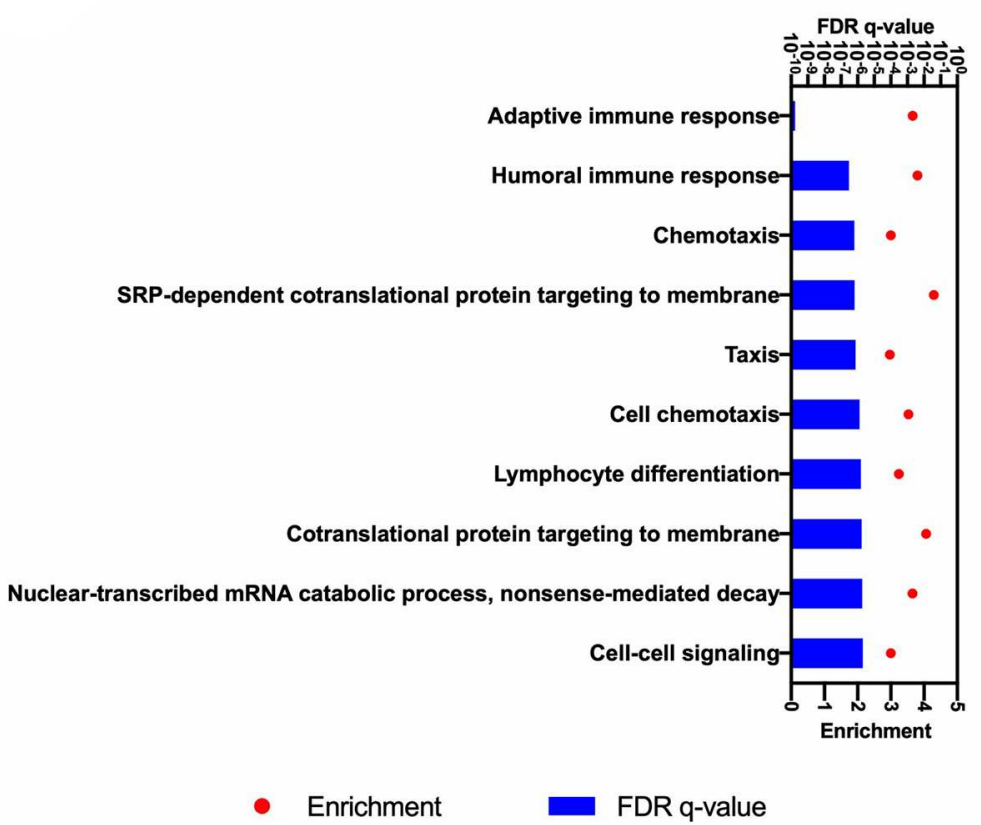

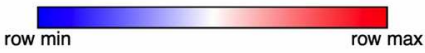

t n m- net

- NM - N

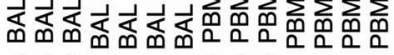

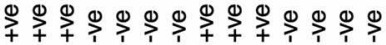

d 主主主主主主主主主主

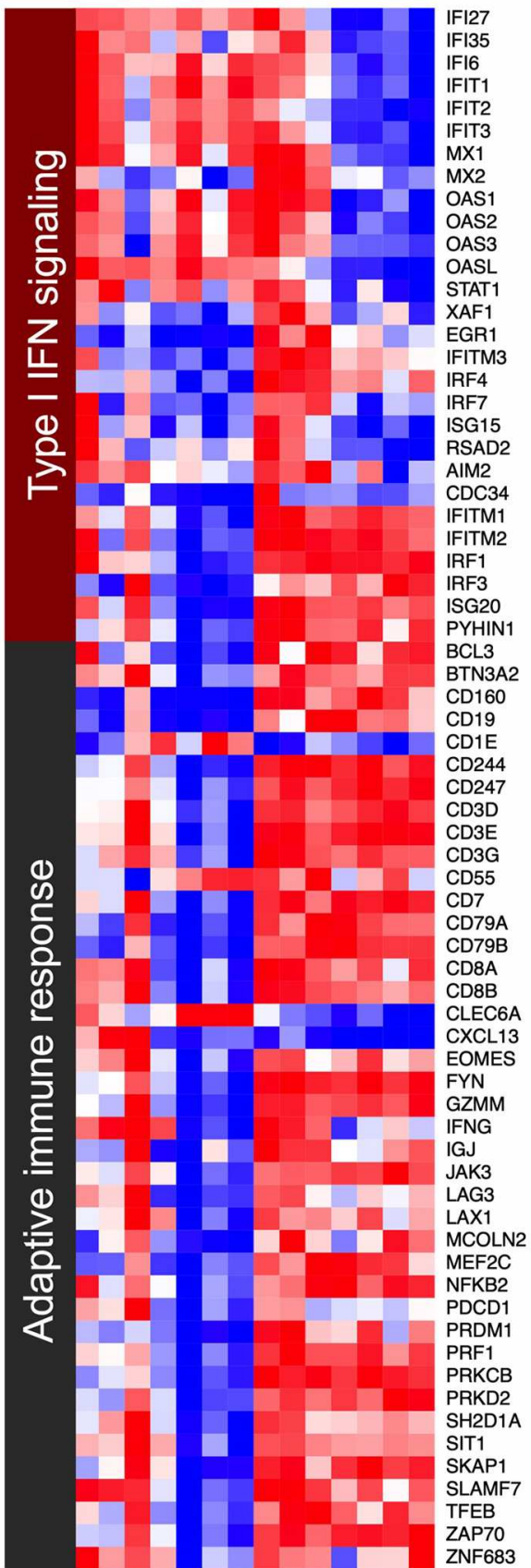

FIGURE 3 | Gene ontology analyses to identify HIV-induced enrichments in bronchoalveolar lavage fluid cells (BLCs) and peripheral blood mononuclear cells (PBMCs). (A) The top $10 \mathrm{HIV}$-associated significantly enriched gene ontology (GO) terms in PBMCs. (B) The top $10 \mathrm{HIV}$-associated significantly enriched gene ontology (GO) terms in BLCs. (C) Heat map showing expression levels of the genes that contribute to the most enriched GO terms in PBMCs and BLCs, i.e., "Type I interferon signaling pathway" and "Adaptive immune response." Natural logarithms of (Expression level +1) were used. 
A

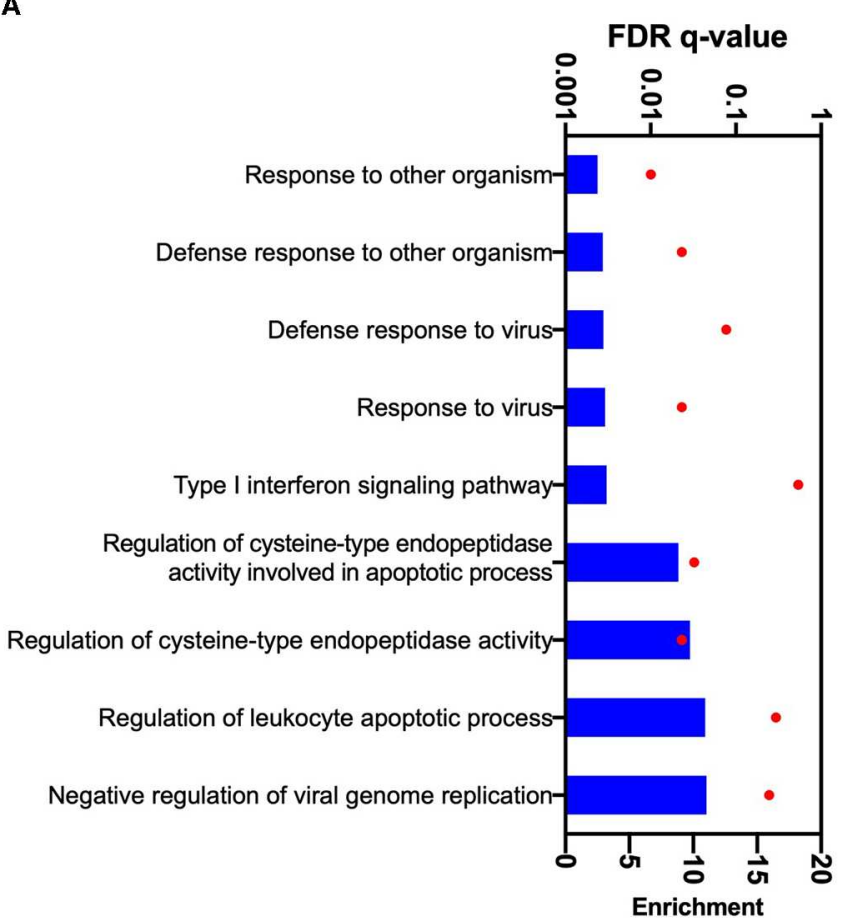

row max

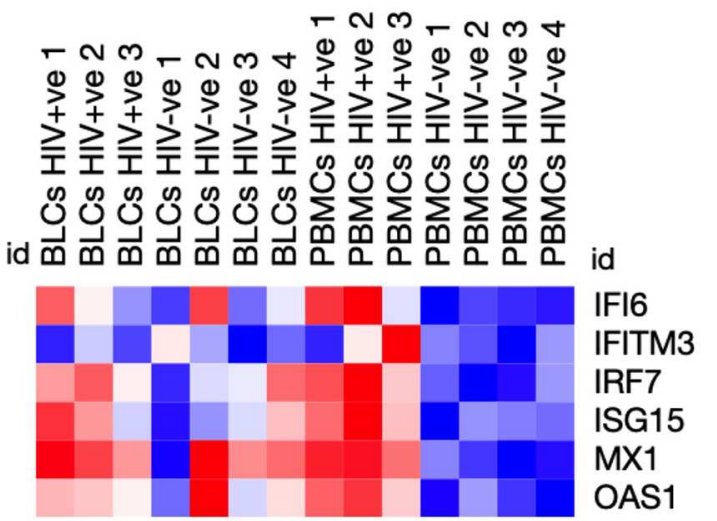

c

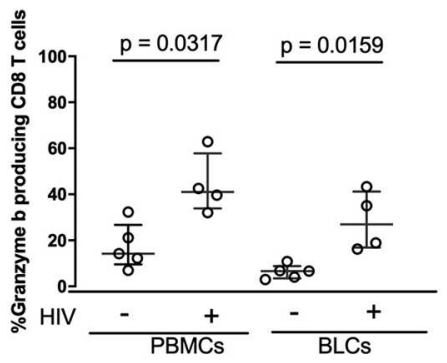

F

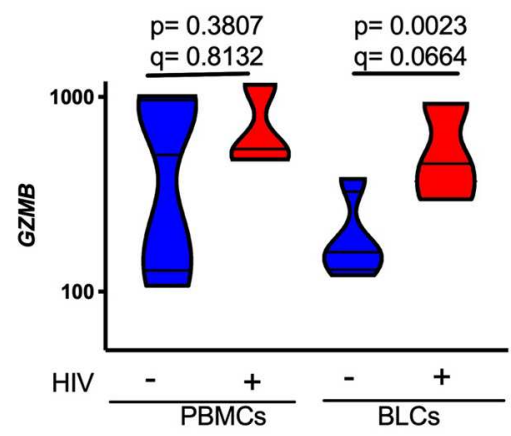

D

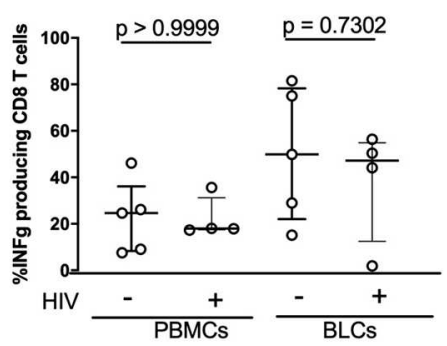

G

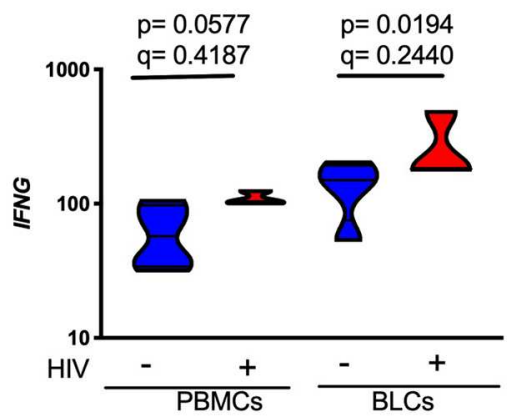

E

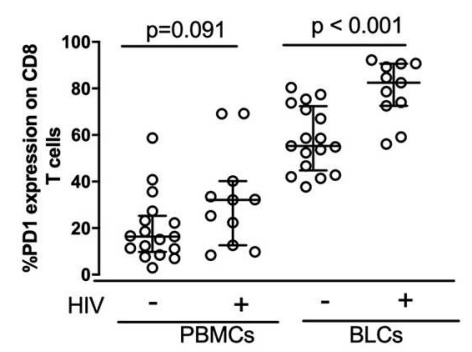

H

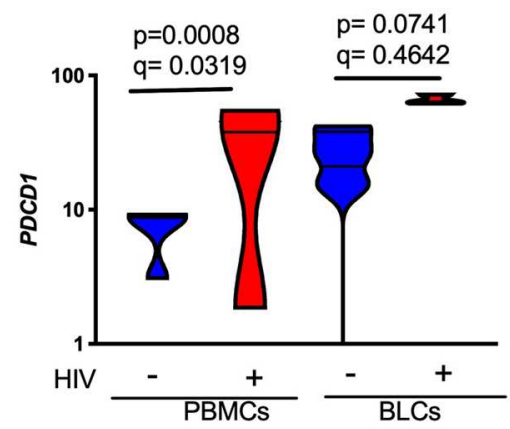

FIGURE 4 | Characterization of HIV-induced changes in PBMCs-derived CD8 T cells and BLCs-derived CD8 T cells. (A) Enriched gene ontology (GO) terms in PBMCs-derived CD8 ${ }^{+}$T cells in comparisons between HIV-positive individuals and HIV-negative individuals. (B) Heat map showing expression levels of type I interferon inducible genes in sorted $\mathrm{CD} 8^{+} \mathrm{T}$ cells. Natural logarithms of (Expression level +1 ) were used. (C) Constitutive expression of granzyme B in unstimulated PBMCs-derived CD8 T cells and BLCs-derived CD8 ${ }^{+} \mathrm{T}$ cells from HIV-positive and HIV-negative participants. (D) Inducible interferon gamma in PBMCs-derived CD8 ${ }^{+}$ T cells and BLCs-derived CD8T cells from HIV-positive and HIV-negative participants. (E) Ex vivo expression of PD-1 in PBMCs-derived CD8 ${ }^{+} \mathrm{T}$ cells and BLCs-derived CD8 T cells in HIV-positive and HIV-negative participants. (F) Expression levels of granzyme B mRNA (GZMB) in BLCs-derived sorted CD8 ${ }^{+}$T cells and 
FIGURE 4 | PBMCs-derived sorted CD8 ${ }^{+}$T cells from HIV-positive and HIV-negative participants. (G) Constitutive expression levels of interferon gamma mRNA (IFNG) in BLCs-derived sorted CD8 ${ }^{+}$T cells and PBMCs-derived sorted CD8 ${ }^{+}$T cells from HIV-positive and HIV-negative participants. (H) Expression levels of PD-1 mRNA (PDCD1) in BLCs-derived and PBMCs-derived sorted CD8 ${ }^{+}$T cells from HIV-positive and HIV-negative participants.

These GO terms included "Response to other organisms," "Defense response to other organism," "Defense response to virus," "Response to virus," and "Type I interferon signaling pathway" (Figure 4A, Supplementary Table 7). In particular, PBMCs-derived $\mathrm{CD}^{+} \mathrm{T}$ cells from HIV-positive individuals had higher expression of IFI6, IFITM3, IRF7, ISG15, MX1, and OAS1 when compared with PBMCs-derived $\mathrm{CD}^{+} \mathrm{T}$ cells from HIV-negative individuals (Figure 4B). There were no GO terms that were enriched among the 16 DEGs in the comparisons between the HIV-positive and HIV-negative BLC-derived $\mathrm{CD}^{+} \mathrm{T}$ cells. Therefore, at both protein and transcript level, we further looked specifically for some target genes that were associated with the "adaptive immune response" GO term in the whole BLC-derived signatures. In agreement with bulk RNA-seq data, there were higher levels of constitutive granzyme $\mathrm{B}$ in $\mathrm{CD}^{+} \mathrm{T}$ cells of $\mathrm{HIV}$-infected individuals in both compartments (Figure 4C). We did not see any differences in inducible interferon gamma protein expression (Figure 4D). There were higher levels of PD1 expression on the $\mathrm{CD} 8^{+} \mathrm{T}$ cells of HIV-infected individuals in both compartments with particularly high levels of PD1 expression in BLC-derived $\mathrm{CD}^{+} \mathrm{T}$ cells (Figure 4E and Supplementary Figures 1C,F). We observed similar trends at the transcript level for granzyme B (GZMB) and PD1 (PDCD1), although HIV infection was associated with a trend of increased constitutive expression of interferon gamma (IFNG) transcripts in both compartments (Figures 4F-H).

\section{DISCUSSION}

$\mathrm{HIV}$ is associated with an increased incidence of both infectious and non-infectious lung morbidities (13, 20, 21). HIV-positive patients have a higher prevalence of Pneumocystis pneumonia, active tuberculosis, bacterial pneumonia, and viral pneumonia $(13,20)$. They also have a higher prevalence of noninfectious structural lung complications such as emphysema and chronic obstructive pulmonary disease (COPD) $(13,21)$.

Despite the high prevalence of HIV-induced lung complications, the immunopathogenesis of HIV in the lung is poorly understood. Due to logistical difficulties of obtaining lung samples, most studies on immune responses to respiratory infections have been conducted in peripheral blood with an assumption that circulating cells have similarities with those in the lung. Here, we show that there are significant differences in the global transcriptional profiles between the blood and the bronchoalveolar compartment, and that the immunological effects of HIV infection revealed by whole compartment transcriptomics in the two compartments are different.

While a type I interferon signature was the most dominant effect of $\mathrm{HIV}$ in PBMCs, a $\mathrm{CD}^{+}$T-cell infiltrate was the dominant effect in the bronchoalveolar compartment. We also observed a weaker and qualitatively different HIV-associated type I interferon signature in the bronchoalveolar compartment of viremic HIV patients. An elevated interferon signature in blood has been associated with progression to TB disease and could arguably relate to the increased susceptibility to TB disease among HIV patients who have a strong type I interferon signature in blood (10). The differences in specific type I interferon gene expression levels between the compartments could be due to the difference in cellular composition. Whether specific lung signatures drive the association of type I interferon signaling with progression from latent to active TB remains largely unknown and can be addressed through the study of the bronchoalveolar compartment in participants who go on to develop TB disease.

Analysis of the cellular composition of the bronchoalveolar compartment in HIV-positive individuals by cell count, flow cytometry, and whole compartment transcriptomics all reflected an infiltration of $\mathrm{CD}^{+} \mathrm{T}$ cells. The $\mathrm{CD} 8^{+} \mathrm{T}$ cell transcriptional analysis demonstrated an enrichment for cellular adhesion and migration associated pathways in the BLC-derived CD8 ${ }^{+} \mathrm{T}$ cells of HIV-positive individuals. The transcriptional comparison of BLC-derived $\mathrm{CD}^{+} \mathrm{T}$ cells between HIV-negative and HIVpositive individuals yielded only 16 differentially expressed genes. It is possible that this is because BLC-derived $\mathrm{CD}^{+} \mathrm{T}$ cells from these two groups are highly similar. An alternative possibility is that our study was limited by relatively low-cell numbers in the sorted samples. Indeed, we observed significant differences between PD-1 and Granzyme B expression at the protein level, suggesting that there are significant differences in the nature of $\mathrm{BLC}$-derived $\mathrm{CD}^{+} \mathrm{T}$ cells between HIVnegative and HIV-positive individuals. Future studies using improved methods and larger sample sizes will be required to confirm the full extent of the differences that might exist in BLCs-derived $\mathrm{CD}^{+} \mathrm{T}$ cells between HIV-positive and HIV-negative individuals. Nevertheless, we show that the $\mathrm{HIV}$-induced $\mathrm{CD}^{+}$T-cell infiltrate is associated with higher expression of granzyme $\mathrm{B}$, suggesting a cytolytic profile. We also report higher expression of PD-1 on BLCs-derived $\mathrm{CD}^{+}$ $\mathrm{T}$ cells of HIV-positive patients. $\mathrm{PD}-1$ expression in $\mathrm{CD}^{+}$ $\mathrm{T}$ cells has been associated with exhaustion (22). However, in juvenile idiopathic arthritis, $\mathrm{PD}-1^{+} \mathrm{CD} 8^{+} \mathrm{T}$ cells derived from synovial fluid were metabolically active functional effector memory $\mathrm{T}$ cells, suggesting that $\mathrm{PD}-1$ expression could also act as a marker of locally adapted functional $\mathrm{T}$ cells (23). Thus, depending on context, PD-1 could be a marker of either exhaustion or local activation in tissues. Even though PD-1 blockade on BLCs-derived T cells from HIV-positive patients was previously shown to boost cytokine secretion in vitro, suggesting exhaustion, there was a counterintuitive increased PD-1 expression among the interferon gamma secreting $\mathrm{T}$ cells 
(19). As such, the implication of HIV-associated increase in PD-1 expression on $\mathrm{CD}^{+} \mathrm{T}$ cells in the bronchoalveolar compartment needs further investigation.

The HIV-induced infiltration of the bronchoalveolar compartment with cytolytic $\mathrm{CD}^{+} \mathrm{T}$ cells could be driven directly by HIV replication (24). The lung has been shown to be a site of HIV replication where small alveolar macrophages and CCR5 expressing CD4 ${ }^{+} \mathrm{T}$ cells are preferentially infected with $\operatorname{HIV}(9,25)$. Infiltrating $\mathrm{CD}^{+} \mathrm{T}$ cells could control local HIV replication by killing the $\mathrm{HIV}$-infected $\mathrm{CD}^{+}{ }^{+} \mathrm{T}$ cells and alveolar macrophages. Indeed, in previous studies, lymphocytic alveolitis in asymptomatic HIV patients was enriched for HIV-specific cytotoxic $\mathrm{CD}^{+} \mathrm{T}$ cells that could execute such effector functions (19). Whether HIV induces bronchoalveolar infiltration with other specificities of $\mathrm{CD}^{+} \mathrm{T}$ cells that can modulate opportunistic respiratory infections, such as tuberculosis, is unclear.

In other settings, CD8 lymphocytic alveolitis has been implicated in the pathogenesis of noninfectious lung complications, such as COPD and emphysema. Considering that HIV infection is also associated with increased prevalence of the same noninfectious lung complications, HIV-induced lymphocytic alveolitis is thought to accelerate the deterioration of lung function in patients who are exposed to other risk factors for COPD and emphysema, such as smokers (24, 26-29). Whether similar bystander destructive mechanisms play an important role in $\mathrm{CD}^{+}$T-cell-mediated disruption of the containment of Mycobacterium tuberculosis in granulomas is unknown. In an immune-competent mouse model, LCMV-specific $\mathrm{CD}^{+} \mathrm{T}$ cells infiltrated Mycobacterium bovis granulomas in the liver, but without conferring any benefit in the control of bacterial growth, suggesting that HIV-specific $\mathrm{CD}^{+}$ $\mathrm{T}$ cells in our setting could also infiltrate $M$. tuberculosis granulomas in human hosts (30). In another mouse model, LCMC-specific cytolytic $\mathrm{CD}^{+} \mathrm{T}$ cells expressing granzyme $\mathrm{B}$ and NKG2D infiltrated Leishmania major lesions and exacerbated disease by causing an exaggerated inflammatory response (31). Infiltrating cytolytic $\mathrm{CD}^{+} \mathrm{T}$ cells in the lung of HIV patients could similarly exaggerate the inflammatory state, disrupting the containment of $M$. tuberculosis in granulomas thus promoting bacterial dissemination. Notably, the $\mathrm{CD}^{+}{ }^{+} \mathrm{T}$-cell infiltrate in our cohorts was characterized by increased expression of granzymes and perforin, suggesting some overlap between the findings in our cohorts and the L. major mouse model (31). Additional studies will be needed to directly interrogate the possible contribution of infiltrating $\mathrm{CD}^{+} \mathrm{T}$ cells in the inflammatory destruction of lung tissues and the anatomical dissemination of $M$. tuberculosis infections.

We conclude that HIV is associated with a cytolytic $\mathrm{CD}^{+}$T-cell infiltrate in the bronchoalveolar compartment. Further mechanistic studies are required to understand the consequences of the infiltration on respiratory infections, such as $M$. tuberculosis, and noninfectious comorbidities, such as COPD and emphysema. Our study did not assess the antigen specificity of the infiltrating $\mathrm{CD}^{+} \mathrm{T}$ cells, although a previous report suggested an enrichment for HIV-specific
$\mathrm{CD}^{+} \mathrm{T}$ cells (19). In future studies, it will be important to determine whether enrichment for $\mathrm{CD}^{+} \mathrm{T}$ cells against respiratory infections, such as $M$. tuberculosis occurs, and the functional competence of these cell. This study was limited by the sample size in the transcriptomic profiling and intracellular cytokine staining. Future studies on larger sample sizes could reveal novel pathways that are induced by HIV in $\mathrm{CD}^{+} \mathrm{T}$ cells that infiltrate the lung mucosal compartment. Nevertheless, our data reveal important compartment-specific effects of HIV in the bronchoalveolar compartment, suggesting a possible mechanism by which HIV modulates immunity to respiratory infections and lung function in ways that cannot be revealed by studying peripheral blood. Furthermore, we show the utility of using whole compartment transcriptomic analyses to reveal infiltration of different sites with various immune cells.

\section{DATA AVAILABILITY STATEMENT}

The datasets generated for this study can be found in the Gene Expression Omnibus (GEO) repository, accession number GSE139327.

\section{ETHICS STATEMENT}

The studies involving human participants were reviewed and approved by University of KwaZulu-Natal Biomedical Research Ethics Committee and Partners Institutional Review Board. The patients/participants provided their written informed consent to participate in this study.

\section{AUTHOR'S NOTE}

This manuscript has been released as a preprint at bioRxiv (32).

\section{AUTHOR CONTRIBUTIONS}

DM, MMt, AS, US, SR, BC, and TB performed the experiments. DM, MMt, AS, DC, and EW did formal analyses. KN, DFK, PM, MMi, MS, ZM, DR, FK, and TNa collected the clinical samples. DSK, TNd, and EW provided supervision. DM, MMt, TNd, and EW wrote the manuscript. All authors reviewed the manuscript and approved the final version.

\section{FUNDING}

Research reported in this publication was supported by the Strategic Health Innovation Partnerships (SHIP) Unit of the South African Medical Research Council with funds received from the South African Department of Science and Innovation as part of a bilateral research collaboration agreement with the Government of India. Other support came from the South Africa Research Chairs Initiative, the Victor Daitz Foundation, a Burroughs-Wellcome Fund/American Society of Tropical Medicine and Hygiene fellowship, the National Institutes of 
Health (K08 AI118538), the Harvard University Center for AIDS Research (grant P30 AI060354), a capacity building Strategic Award awarded to the KEMRI-Wellcome Trust Research Programme and the South Africa National Research Foundation. Additional support was received through the SubSaharan African Network for TB/HIV Research Excellence (SANTHE), a DELTAS Africa Initiative [grant no. DEL-15006]. The DELTAS Africa Initiative is an independent funding scheme of the African Academy of Sciences (AAS)'s Alliance for Accelerating Excellence in Science in Africa (AESA) and

\section{REFERENCES}

1. UNAIDS. DATA. (2019). Available online at: https://www.unaids.org/sites/ default/files/media_asset/2019-UNAIDS-data_en.pdf (accessed September 4, 2019).

2. UNAIDS. Tuberculosis and HIV. (2019). Available online at: https://www. unaids.org/sites/default/files/media_asset/tuberculosis-and-hiv-progresstowards-the-2020-target_en.pdf (accessed May 6, 2019).

3. Fenner L, Atkinson A, Boulle A, Fox MP, Prozesky H, Zurcher K, et al. HIV viral load as an independent risk factor for tuberculosis in South Africa: collaborative analysis of cohort studies. J Int AIDS Soc. (2017) 20:21327. doi: 10.7448/IAS.20.1.21327

4. Caruso AM, Serbina N, Klein E, Triebold K, Bloom BR, Flynn JL. Mice deficient in CD4 $\mathrm{T}$ cells have only transiently diminished levels of IFN- $\gamma$, yet succumb to tuberculosis. J Immunol. (1999) 162:5407-16.

5. Flynn JL, Chan J, Triebold KJ, Dalton DK, Stewart TA, Bloom BR. An essential role for interferon gamma in resistance to Mycobacterium tuberculosis infection. J Exp Med. (1993) 178:2249-54. doi: 10.1084/jem.178. 6.2249

6. Sonnenberg P, Glynn JR, Fielding K, Murray J, Godfrey-Faussett P, Shearer S. How soon after infection with HIV does the risk of tuberculosis start to increase? A retrospective cohort study in South African gold miners. J Infect Dis. (2005) 191:150-8. doi: 10.1086/426827

7. Day CL, Abrahams DA, Harris LD, van Rooyen M, Stone L, de Kock M, et al. HIV-1 infection is associated with depletion and functional impairment of Mycobacterium tuberculosis-specific CD4 T cells in individuals with latent tuberculosis infection. J Immunol. (2017) 199:2069-80. doi: 10.4049/jimmunol.1700558

8. Jambo KC, Banda DH, Afran L, Kankwatira AM, Malamba RD, Allain TJ, et al. Asymptomatic HIV-infected individuals on antiretroviral therapy exhibit impaired lung $\mathrm{CD}^{+}$T-cell responses to mycobacteria. Am J Respir Crit Care Med. (2014) 190:938-47. doi: 10.1164/rccm.201405-0 $8640 \mathrm{OC}$

9. Jambo KC, Banda DH, Kankwatira AM, Sukumar N, Allain TJ, Heyderman RS, et al. Small alveolar macrophages are infected preferentially by HIV and exhibit impaired phagocytic function. Mucosal Immunol. (2014) 7:1116-26. doi: $10.1038 / \mathrm{mi} .2013 .127$

10. Berry MP, Graham CM, McNab FW, Xu Z, Bloch SA, Oni T, et al. An interferon-inducible neutrophil-driven blood transcriptional signature in human tuberculosis. Nature. (2010) 466:973-7. doi: 10.1038/nature 09247

11. Sweeney TE, Braviak L, Tato CM, Khatri P. Genome-wide expression for diagnosis of pulmonary tuberculosis: a multicohort analysis. Lancet Respir Med. (2016) 4:213-24. doi: 10.1016/S2213-2600(16)00048-5

12. Warsinske H, Vashisht $\mathrm{R}$, Khatri P. Host-response-based gene signatures for tuberculosis diagnosis: a systematic comparison of 16 signatures. PLoS Med. (2019) 16:e1002786. doi: 10.1371/journal.pmed.10 02786

13. Beck JM, Rosen MJ, Peavy HH. Pulmonary complications of HIV infection. Report of the Fourth NHLBI Workshop. Am J Respir Crit Care Med. (2001) 164:2120-6. doi: 10.1164/ajrccm.164.11. 2102047 supported by the New Partnership for Africas Development Planning and Coordinating Agency (NEPAD Agency) with funding from the Wellcome Trust [grant no. 107752/Z/15/Z] and the UK government.

\section{SUPPLEMENTARY MATERIAL}

The Supplementary Material for this article can be found online at: https://www.frontiersin.org/articles/10.3389/fimmu. 2020.00864/full\#supplementary-material

14. Bosinger SE, Utay NS. Type I interferon: understanding its role in HIV pathogenesis and therapy. Curr HIV/AIDS Rep. (2015) 12:41-53. doi: 10.1007/s11904-014-0244-6

15. Trapnell C, Roberts A, Goff L, Pertea G, Kim D, Kelley DR, et al. Differential gene and transcript expression analysis of RNA-seq experiments with TopHat and Cufflinks. Nat Protoc. (2012) 7:562-78. doi: 10.1038/nprot.20 12.016

16. Eden E, Navon R, Steinfeld I, Lipson D, Yakhini Z. GOrilla: a tool for discovery and visualization of enriched GO terms in ranked gene lists. BMC Bioinform. (2009) 10:48. doi: 10.1186/1471-2105-10-48

17. Newman AM, Liu CL, Green MR, Gentles AJ, Feng W, Xu Y, et al. Robust enumeration of cell subsets from tissue expression profiles. Nat Methods. (2015) 12:453-7. doi: 10.1038/nmeth.3337

18. Mwale A, Hummel A, Mvaya L, Kamngóna R, Chimbayo E, Phiri J, et al. B cell, $\mathrm{CD}^{+} \mathrm{T}$ cell and gamma delta $\mathrm{T}$ cell infiltration alters alveolar immune cell homeostasis in HIV-infected Malawian adults. Wellcome Open Res. (2017) 2:105. doi: 10.12688/wellcomeopenres.12869.2

19. Neff CP, Chain JL, MaWhinney S, Martin AK, Linderman DJ, Flores SC, et al. Lymphocytic alveolitis is associated with the accumulation of functionally impaired HIV-specific $\mathrm{T}$ cells in the lung of antiretroviral therapy-naive subjects. Am J Respir Crit Care Med. (2015) 191:464-73. doi: $10.1164 / \mathrm{rccm} .201408-15210 \mathrm{C}$

20. Diedrich CR, Flynn JL. HIV-1/mycobacterium tuberculosis coinfection immunology: how does HIV-1 exacerbate tuberculosis? Infect Immun. (2011) 79:1407-17. doi: 10.1128/IAI.01126-10

21. Staitieh B, Guidot DM. Noninfectious pulmonary complications of human immunodeficiency virus infection. Am J Med Sci. (2014) 348:502-11. doi: 10.1097/MAJ.0000000000000318

22. McLane LM, Abdel-Hakeem MS, Wherry EJ. CD8 T cell exhaustion during chronic viral infection and cancer. Annu Rev Immunol. (2019) 37:457-95. doi: 10.1146/annurev-immunol-041015-055318

23. Petrelli A, Mijnheer G, Hoytema van Konijnenburg DP, van der Wal MM, Giovannone B, Mocholi E, et al. PD- $1^{+} \mathrm{CD} 8^{+} \mathrm{T}$ cells are clonally expanding effectors in human chronic inflammation. J Clin Invest. (2018) 128:4669-81. doi: 10.1172/JCI96107

24. Twigg HL, Soliman DM, Day RB, Knox KS, Anderson RJ, Wilkes DS, et al. Lymphocytic alveolitis, bronchoalveolar lavage viral load, and outcome in human immunodeficiency virus infection. Am J Respir Crit Care Med. (1999) 159(5 Pt 1):1439-44. doi: 10.1164/ajrccm.159.5.9808031

25. Corleis B, Bucsan AN, Deruaz M, Vrbanac VD, Lisanti-Park AC, Gates SJ, et al. HIV-1 and SIV infection are associated with early loss of lung interstitial $\mathrm{CD}^{+} \mathrm{T}$ cells and dissemination of pulmonary tuberculosis. Cell Rep. (2019) 26:1409-18.e5. doi: 10.1016/j.celrep.2019.01.021

26. Popescu I, Drummond MB, Gama L, Lambert A, Hoji A, Coon T, et al. HIV suppression restores the lung mucosal $\mathrm{CD} 4^{+} \mathrm{T}$-cell viral immune response and resolves $\mathrm{CD}^{+}$T-cell alveolitis in patients at risk for HIV-associated chronic obstructive pulmonary disease. J Infect Dis. (2016) 214:1520-30. doi: 10.1093/infdis/jiw422

27. Petrache I, Diab K, Knox KS, Twigg HL 3rd, Stephens RS, Flores S, et al. HIV associated pulmonary emphysema: a review of the literature and inquiry into its mechanism. Thorax. (2008) 63:463-9. doi: 10.1136/thx.2007.0 79111 
28. Crothers K, Huang L, Goulet JL, Goetz MB, Brown ST, Rodriguez-Barradas $\mathrm{MC}$, et al. HIV infection and risk for incident pulmonary diseases in the combination antiretroviral therapy era. Am J Respir Crit Care Med. (2011) 183:388-95. doi: 10.1164/rccm.201006-0836OC

29. Plata F, Autran B, Martins LP, Wain-Hobson S, Raphael M, Mayaud C, et al. AIDS virus-specific cytotoxic T lymphocytes in lung disorders. Nature. (1987) 328:348-51. doi: 10.1038/328348a0

30. Hogan LH, Co DO, Karman J, Heninger E, Suresh M, Sandor M. Virally activated CD8 T cells home to Mycobacterium bovis BCGinduced granulomas but enhance antimycobacterial protection only in immunodeficient mice. Infect Immun. (2007) 75:1154-66. doi: 10.1128/IAI.00943-06

31. Crosby EJ, Goldschmidt $\mathrm{MH}$, Wherry EJ, Scott P. Engagement of NKG2D on bystander memory CD8 T cells promotes increased immunopathology following Leishmania major infection. PLoS Pathog. (2014) 10:e1003970. doi: 10.1371/journal.ppat.10 03970

32. Muema DM, Mthembu M, Schiff A, Singh U, Corleis B, Bassett T, et al. Contrasting inflammatory signatures in peripheral blood and bronchoalveolar cells reveal compartment-specific effects of HIV infection. bioRxiv. (2019) [preprint]. doi: 10.1101/804229

Disclaimer: The views expressed in this publication are those of the author(s) and not necessarily those of AAS, NEPAD Agency,Wellcome Trust, or the UK government.

Conflict of Interest: The authors declare that the research was conducted in the absence of any commercial or financial relationships that could be construed as a potential conflict of interest.

Copyright (c) 2020 Muema, Mthembu, Schiff, Singh, Corleis, Chen, Bassett, Rasehlo, Nyamande, Khan, Maharaj, Mitha, Suleman, Mhlane, Naidoo, Ramjit, Karim, Kwon, Ndung'u and Wong. This is an open-access article distributed under the terms of the Creative Commons Attribution License (CC BY). The use, distribution or reproduction in other forums is permitted, provided the original author(s) and the copyright owner(s) are credited and that the original publication in this journal is cited, in accordance with accepted academic practice. No use, distribution or reproduction is permitted which does not comply with these terms. 